\title{
Phytochemical characterization and antioxidant activity of Opuntia microdasys (Lehm.) Pfeiff flowers in different stages of maturity
}

Hassiba Chahdoura $^{\mathrm{a}, \mathrm{b}}$, João C.M. Barreira ${ }^{\mathrm{a}, \mathrm{c}}$, Lillian Barros ${ }^{\mathrm{a}}$, Celestino Santos-Buelga ${ }^{\mathrm{c}}$, Isabel C.F.R. Ferreira ${ }^{\mathrm{a}, *}$, Lotfi Achour ${ }^{\mathrm{b}}$

${ }^{a}$ Mountain Research Centre (CIMO), ESA, Polytechnic Institute of Bragança, Campus de Santa Apolónia, Ap. 1172, 5301-855 Bragança, Portugal.

${ }^{b}$ Unité de Recherche 03/UR/09-01 «Génome, Diagnostic Immunitaire et Valorisation», Institut Supérieur de Biotechnologie de Monastir, Avenue Tahar Hadded, BP 74, 5000, Université de Monastir, Monastir, Tunisia.

${ }^{c}$ Grupo de Investigación en Polifenoles (GIP-USAL), Faculty of Pharmacy, University of Salamanca, Campus Miguel de Unamuno, 37007 Salamanca, Spain.

*Author to whom correspondence should be addressed (e-mail: iferreira@ipb.pt, telephone +351273303219 , fax +351273325405$)$. 


\begin{abstract}
The diversity of Opuntia spp. bioactive molecules makes them good candidates for production of health promoting foods. The chemical composition of $O$. microdasys flowers in different maturity stages was profiled with respect to hydrophilic and lipophilic compounds. Furthermore, the antioxidant activity was evaluated though radicals scavenging activity, reducing power and lipid peroxidation inhibition. Soluble sugars profile revealed the presence of fructose, glucose, sucrose and trehalose; the detected organic acids were oxalic, quinic, malic, and citric acid; phenolic compounds included five hydroxycinnamoyl, two kaempferol and six isorhamnetin derivatives; twenty three fatty acids were quantified in all flowering stages, except C20:2, which was only found in post flowering stage (F3); $\alpha-, \beta-, \gamma$-, and $\delta$-tocopherols were quantified in all samples. The highest contents in soluble sugars and phenolic compounds were detected in full flowering stage (F2), while organic acids and tocopherols were predominant in vegetative stage (F1). The highest levels of saturated, monounsaturated and polyunsaturated fatty acids were found in F3, F2 and F1, respectively. F1 gave the highest antioxidant activity. Principal components analysis showed clearly individualized groups corresponding to each flowering stage, identifying the most distinctive features, which might be useful to select a flowering stage for incorporation in functional foods.
\end{abstract}

Keywords: Opuntia microdasys; flowering stage; phytochemicals; antioxidant activity; PCA; functional foods 


\section{Introduction}

The cactus plant (Opuntia spp.) belongs to the Cactaceae family; it is native to Mexico, being widespread throughout Central and South America, Australia, South Africa, but also throughout the whole Mediterranean area. These plants grow wild in arid and semiarid regions, where the production of more succulent food plants is severely limited (Galati et al., 2002). Opuntia spp. did not receive much attention by the scientific community until the beginning of 1980, but an increase of research works and publications on the chemical characterization of the flowers and other organs of these plants occurred. This renewed interest might be ascribed to the multi-functionality of Opuntia spp. fruits, pads, and flowers, due to the great number of potentially active nutrients that offer interesting opportunities for the production of health promoting food and food supplements (Stintzing \& Carle, 2005). In fact, Opuntia ssp. species has also been gradually achieving economic importance due to FAO recommendations, which strengthened an increased cooperation among scientists, technicians and growers from different countries, facilitating the exchange of information, knowledge and technical cooperation on cactus, contributing to the diffusion of its cultivation (Galati et al., 2002).

Antioxidants and radical scavengers are considered important nutraceuticals, exerting a protective effect in several diseases (Feugang et al., 2006). Moreover, it has been well documented that natural polyphenolic compounds have a close relationship with these properties (Heim et al., 2002; Pallarès et al., 2013). Oxidative stress and deficient antioxidant defences have been implicated in some clinical disorders. Therefore, dietderived antioxidants may be particularly important in protecting against chronic diseases (Carocho \& Ferreira, 2013). In recent years, considerable attention has been 
directed towards identification of natural antioxidants (plant derived) that may be used as food supplements able to promote health (Senanayake et al., 2013).

The flowers of Opuntia genus are used in traditional Tunisian and Italian (Sicily) medicine. Their infusions, for instance, are known as diuretic agents and as having the capacity to expulse renal calculus and cure ulcer (Yeddes et al., 2014). Flower extracts (50\% aqueous methanol and ethanol) of $O$. ficus indica f. inermis, $O$. ficus indica (L.), O. stricta (Haw.) have shown anti-fungicide, anti-bacterial, antioxidant and antiulcerogenic activities (Alimi et al.; 2011; Ammar et al., 2012). Isorhamnetin glycosylated compounds were reported as the major phenolic compounds in flowers from O. ficus indica from Italy (Leo et al., 2010) and Tunisia (Yeddes et al., 2014). However, as far as we know, there are no reports concerning phytochemical composition of $O$. microdasys flowers.

In this context, the present work aims to compare the chemical composition of flowers of $O$. microdasys in different maturity stages, with respect to hydrophilic (soluble sugars, organic acids and phenolic compounds) and lipophilic (fatty acids and tocopherols) molecules. Furthermore, in vitro antioxidant properties (free radicals scavenging activity, reducing power and lipid peroxidation inhibition) of their methanolic extracts were evaluated and compared to the corresponding phytochemical profile, in order to establish the most adequate stages to be incorporated in functional foods, for instance using microencapsulation techniques, and/or to develop nutraceutical formulations like capsules, pills or syrups.

\section{Materials and methods}

\subsection{Sample}


Opuntia microdasys flowers were collected from the cliff of Monastir (Tunisia) at three phenological stages: (F1) vegetative stage, with green closed petal flowers; (F2) full flowering stage: stamens are separated around the stylet and the flowers are fully opened and the nectar production starts; (F3) post flowering stage: the flowers are dried and close to senescence. All samples were collected during 2013: F1 samples were harvested in the beginning of June; F2 were harvested after the first fortnight; F3 samples were obtained in the last week of June. Opuntia microdasys flowers were dried under shade, grounded with a Warring blender (Phillips, France), reduced to a fine dried powder (20 mesh) and mixed to obtain a homogenous sample.

\subsection{Standards and reagents}

Acetonitrile (99.9\%), n-hexane (97\%) and ethyl acetate $(99.8 \%)$ were of HPLC grade from Fisher Scientific (Lisbon, Portugal). The fatty acids methyl ester (FAME) reference standard mixture 37 (standard 47885-U) was purchased from Sigma (St. Louis, MO, USA), as also were other individual fatty acid isomers and standards: Lascorbic acid, tocopherols ( $\alpha-, \beta-, \gamma$-, and $\delta$-isoforms), soluble sugars ( $\mathrm{D}(-)$-fructose, $\mathrm{D}(+)$-melezitose, $\mathrm{D}(+)$-sucrose, $\mathrm{D}(+)$-glucose, $\mathrm{D}(+)$-trehalose and $\mathrm{D}(+)$-raffinose pentahydrate), organic acids and trolox (6-hydroxy-2,5,7,8-tetramethylchroman-2carboxylic acid). Phenolic compounds were purchased from Extrasynthèse (Genay, France). Racemic tocol, $50 \mathrm{mg} / \mathrm{mL}$, was purchased from Matreya (Pleasant Gap, PA, USA). 2,2-Diphenyl-1-picrylhydrazyl (DPPH) was obtained from Alfa Aesar (Ward Hill, MA, USA). Water was treated in a Milli-Q water purification system (TGI Pure Water Systems, Greenville, SC, USA). All other chemicals and solvents were of analytical grade and purchased from common sources. 


\subsection{Chemical composition in hydrophilic compounds}

\subsubsection{Soluble sugars}

Soluble sugars were determined by high performance liquid chromatography coupled to a refraction index detector (HPLC-RI). Dried sample powder $(1.0 \mathrm{~g})$ was spiked with the melezitose as internal standard (IS, $5 \mathrm{mg} / \mathrm{mL}$ ), and was extracted with $40 \mathrm{~mL}$ of $80 \%$ aqueous ethanol at $80{ }^{\circ} \mathrm{C}$ for $30 \mathrm{~min}$. The resulting suspension was centrifuged (Centurion K24OR refrigerated centrifuge, West Sussex, UK) at 15,000g for $10 \mathrm{~min}$. The supernatant was concentrated at $60{ }^{\circ} \mathrm{C}$ under reduced pressure and defatted three times with $10 \mathrm{~mL}$ of ethyl ether, successively. After concentration at $40{ }^{\circ} \mathrm{C}$, the solid residues were dissolved in water to a final volume of $5 \mathrm{~mL}$ and filtered through $0.2 \mu \mathrm{m}$ nylon filters from Whatman (Pinela et al., 2012). The equipment of analysis consisted of an integrated system with a pump (Knauer, Smartline system 1000, Brelin, Germany), degasser system (Smartline manager 5000), auto sampler (AS-2057 Jasco, Easton, MD, USA) and an RI detector (Knauer Smartline 2300). Data were analysed using Clarity 2.4 Software (DataApex). The chromatographic separation was achieved with a Eurospher $100-5 \mathrm{NH}_{2}$ column $(4.6 \times 250 \mathrm{~mm}, 5 \mathrm{~mm}$, Knauer $)$ operating at $30^{\circ} \mathrm{C}$ (7971 R Grace oven). The mobile phase was acetonitrile/deionized water (70:30, $v / v)$ at

a flow rate of $1 \mathrm{~mL} / \mathrm{min}$. The compounds were identified by chromatographic comparisons with authentic standards. Quantification was performed using the internal standard method and soluble sugars contents were further expressed in g per $100 \mathrm{~g}$ of dry weight (dw).

\subsubsection{Organic acids}

Organic acids were determined using ultra-fast liquid chromatography coupled to a photodiode array detector (UFLC-PDA). Samples ( $\sim 2 \mathrm{~g})$ were extracted by stirring with 
$25 \mathrm{~mL}$ of meta-phosphoric acid $\left(25^{\circ} \mathrm{C}\right.$ at $\left.150 \mathrm{rpm}\right)$ for $45 \mathrm{~min}$ and subsequently filtered through Whatman No. 4 paper. Before analysis, the sample was filtered through $0.2 \mu \mathrm{m}$ nylon filters (Barros et al., 2013). The analysis was performed using a Shimadzu 20A series UFLC (Shimadzu Corporation, Kyoto, Japan). Separation was achieved on a SphereClone (Phenomenex, Torrance, CA, USA) reverse phase $\mathrm{C}_{18}$ column (5 $\mu \mathrm{m}, 250$ $\mathrm{mm} \times 4.6 \mathrm{~mm}$ i.d.) thermostatted at $35^{\circ} \mathrm{C}$. The elution was performed with sulphuric acid $(3.6 \mathrm{mM})$ using a flow rate of $0.8 \mathrm{~mL} / \mathrm{min}$. Detection was carried out in a PDA, using 215 and $245 \mathrm{~nm}$ (for ascorbic acid) as preferred wavelengths. The organic acids found were quantified by comparison of the area of their peaks recorded at 215 and 245 nm with calibration curves obtained from commercial standards of each compound: ascorbic acid $\left(\mathrm{y}=8 \mathrm{E}+07 \mathrm{x}+55079 ; R^{2}=1\right)$; citric $\left(\mathrm{y}=1 \mathrm{E}+06 \mathrm{x}+4170.6 ; R^{2}=1\right)$; fumaric acid $\left(\mathrm{y}=172760 \mathrm{x}+52193 ; R^{2}=0.999\right) ;$ malic acid $\left(\mathrm{y}=952269 \mathrm{x}+17803 ; R^{2}=1\right) ;$ oxalic acid

$\left(\mathrm{y}=1 \mathrm{E}+07 \mathrm{x}+96178 ; R^{2}=0.999\right)$ and quinic acid $\left(\mathrm{y}=601768 \mathrm{x}+8853.2 ; R^{2}=1\right)$. The results were expressed in g per $100 \mathrm{~g}$ of dry weight $(\mathrm{dw})$.

\subsubsection{Phenolic compounds}

The powdered plant samples $(\sim 1 \mathrm{~g})$ were extracted by stirring with $30 \mathrm{~mL}$ of methanol/water $(80: 20, v / v)$, at room temperature, $150 \mathrm{rpm}$, for $1 \mathrm{~h}$. The extract was filtered through Whatman $n^{\circ} 4$ paper. The residue was then re-extracted twice with additional portions $(30 \mathrm{~mL})$ of methanol/water $(80: 20, v / v)$. The combined extracts were evaporated at $35{ }^{\circ} \mathrm{C}$ (rotary evaporator Büchi R-210, Flawil, Switzerland) to remove methanol. The aqueous phase was lyophilized and re-dissolved in $20 \%$ aqueous methanol at $5 \mathrm{mg} / \mathrm{mL}$ and filtered through a $0.22-\mu \mathrm{m}$ disposable LC filter disk for high performance liquid chromatography (HPLC-DAD-MS) analysis. The extracts were analysed using a Hewlett-Packard 1100 chromatograph (Agilent Technologies, Santa 
Clara, CA, USA) with a quaternary pump and a diode array detector (DAD) coupled to an HP Chem Station (rev. A.05.04) data-processing station. A Waters Spherisorb S3 ODS-2 $\mathrm{C}_{18}, 3 \mu \mathrm{m}(4.6 \mathrm{~mm} \times 150 \mathrm{~mm})$ column thermostatted at $35{ }^{\circ} \mathrm{C}$ was used. The solvents used were: (A) $0.1 \%$ formic acid in water, (B) acetonitrile. The elution gradient established was isocratic $15 \%$ for $5 \mathrm{~min}, 15 \%$ B to $20 \%$ B over $5 \mathrm{~min}, 20-25 \%$ B over $10 \mathrm{~min}, 25-35 \%$ B over $10 \mathrm{~min}, 35-50 \%$ for $10 \mathrm{~min}$, and re-equilibration of the column, using a flow rate of $0.5 \mathrm{~mL} / \mathrm{min}$. Double online detection was carried out in the DAD using $280 \mathrm{~nm}$ and $370 \mathrm{~nm}$ as preferred wavelengths and in a mass spectrometer (MS) connected to HPLC system via the DAD cell outlet.

MS detection was performed in an API 3200 Qtrap (Applied Biosystems, Darmstadt, Germany) equipped with an ESI source and a triple quadrupole-ion trap mass analyzer that was controlled by the Analyst 5.1 software. Zero grade air served as the nebulizer gas (30 psi) and turbo gas for solvent drying (400 $\left.{ }^{\circ} \mathrm{C}, 40 \mathrm{psi}\right)$. Nitrogen served as the curtain (20 psi) and collision gas (medium). The quadrupols were set at unit resolution. The ion spray voltage was set at $-4500 \mathrm{~V}$ in the negative mode. The MS detector was programmed for recording in two consecutive modes: Enhanced MS (EMS) and enhanced product ion (EPI) analysis. EMS was employed to show full scan spectra, so as to obtain an overview of all of the ions in sample. Settings used were: declustering potential (DP) $-450 \mathrm{~V}$, entrance potential (EP) $-6 \mathrm{~V}$, collision energy (CE) -10V. EPI mode was performed in order to obtain the fragmentation pattern of the parent ion(s) in the previous scan using the following parameters: DP $-50 \mathrm{~V}, \mathrm{EP}-6 \mathrm{~V}, \mathrm{CE}-25 \mathrm{~V}$, and collision energy spread (CES) $0 \mathrm{~V}$. Spectra were recorded in negative ion mode between $m / z 100$ and 1000.

The phenolic compounds present in the samples were characterised according to their UV and mass spectra and retention times compared with standards when available. For 
the quantitative analysis of phenolic compounds, a 5-level calibration curve was obtained by injection of known concentrations $(2.5-100 \mu \mathrm{g} / \mathrm{mL})$ of different standard compounds: $p$-coumaric acid $\left(\mathrm{y}=884.6 \mathrm{x}+184.49 ; R^{2}=0.999\right)$; caffeic acid $(\mathrm{y}=611.9 \mathrm{x}-$ $\left.4.573 ; \quad R^{2}=0.999\right) ; \quad$ ferulic acid $\left(\mathrm{y}=505.97 \mathrm{x}-64.578 ; \quad R^{2}=0.999\right) ; \quad$ kaempferol-3-O rutinoside $\left(\mathrm{y}=239.16 \mathrm{x}-10.587 ; R^{2}=1\right)$; isorhamnetin-3- $O$-rutinoside $(\mathrm{y}=327.42 \mathrm{x}+313.78$; $\left.R^{2}=1\right)$ and isorhamnetin-3-O-glucoside $\left(\mathrm{y}=262.31 \mathrm{x}+9.8958 ; R^{2}=1\right)$. The results were expressed in $\mu \mathrm{g}$ per $\mathrm{g}$ of extract.

\subsection{Chemical composition in lipophilic compounds}

\subsubsection{Fatty acids}

Fatty acids were determined by gas-liquid chromatography with flame ionization detection (GC-FID)/capillary column, after trans-esterification procedure. Fatty acids (obtained after Soxhlet extraction of $\approx 3 \mathrm{~g}$ of dry flowers) were methylated with $5 \mathrm{~mL}$ of methanol/sulphuric acid/toluene $(2: 1: 1, v / v / v)$, during at least $12 \mathrm{~h}$ in a bath at $50{ }^{\circ} \mathrm{C}$ and $160 \mathrm{rpm}$; then $3 \mathrm{~mL}$ of deionised water were added, to obtain phase separation; the FAME were recovered with $3 \mathrm{~mL}$ of diethyl ether by shaking in vortex, and the upper phase was passed through a micro-column of anhydrous sodium sulphate, in order to eliminate the water; the sample was recovered in a vial with Teflon, and before injection the sample was filtered with $0.2 \mu \mathrm{m}$ nylon filter from Whatman (Pinela et al., 2012). The analysis was carried out with a DANI model GC 1000 instrument equipped with a split/splitless injector, a flame ionization detector (FID at $260^{\circ} \mathrm{C}$ ) and a MachereyNagel (Düren, Germany) column $\quad(50 \%$ cyanopropyl methyl-50\% phenylmethylpolysiloxane, $30 \mathrm{~m} \times 0.32 \mathrm{~mm}$ i.d. $\times 0.25 \mu \mathrm{m} \mathrm{d}$ ). The oven temperature program was as follows: the initial temperature of the column was $50^{\circ} \mathrm{C}$, held for $2 \mathrm{~min}$, then a $30{ }^{\circ} \mathrm{C} / \mathrm{min}$ ramp to $125^{\circ} \mathrm{C}, 5^{\circ} \mathrm{C} / \mathrm{min}$ ramp to $160{ }^{\circ} \mathrm{C}, 20{ }^{\circ} \mathrm{C} / \mathrm{min}$ ramp to $180{ }^{\circ} \mathrm{C}$, 
$3{ }^{\circ} \mathrm{C} / \mathrm{min}$ ramp to $200{ }^{\circ} \mathrm{C}, 20{ }^{\circ} \mathrm{C} / \mathrm{min}$ ramp to $220^{\circ} \mathrm{C}$ and held for $15 \mathrm{~min}$. The carrier gas (hydrogen) flow-rate was $4.0 \mathrm{~mL} / \mathrm{min}(0.61$ bar $)$, measured at $50{ }^{\circ} \mathrm{C}$. Split injection (1:40) was carried out at $250{ }^{\circ} \mathrm{C}$. Fatty acid identification was made by comparing the relative retention times of FAME peaks from samples with standards. The results were recorded and processed using the CSW 1.7 Software (DataApex 1.7) and expressed in relative percentage of each fatty acid.

\subsubsection{Tocopherols}

Tocopherols were determined by HPLC (equipment described above), and a fluorescence detector (FP-2020; Jasco). A solution of butylated hydroxytoluene (BHT) in hexane $(10 \mathrm{mg} / \mathrm{mL} ; 100 \mu \mathrm{L})$ and IS solution in hexane (tocol; $50 \mu \mathrm{g} / \mathrm{mL} ; 400 \mu \mathrm{L}$ ) were added to the sample prior to the extraction procedure. The samples $(\sim 500 \mathrm{mg})$ were homogenized with methanol $(4 \mathrm{~mL})$ by vortex mixing $(1 \mathrm{~min})$. Subsequently, hexane $(4 \mathrm{~mL})$ was added and again vortex mixed for $1 \mathrm{~min}$. After that, saturated $\mathrm{NaCl}$ aqueous solution $(2 \mathrm{~mL})$ was added, the mixture was homogenized $(1 \mathrm{~min})$, centrifuged (5 min, 4000g) and the clear upper layer was carefully transferred to a vial. The sample was re-extracted twice with hexane. The combined extracts were taken to dryness under a nitrogen stream, redissolved in $2 \mathrm{~mL}$ of $\mathrm{n}$-hexane, dehydrated with anhydrous sodium sulphate, filtered through $0.2 \mu \mathrm{m}$ nylon filters from Whatman, transferred into a dark injection vial prior to the analysis (Pinela et al., 2012). The fluorescence detector was programmed for excitation at $290 \mathrm{~nm}$ and emission at $330 \mathrm{~nm}$. The chromatographic separation was achieved with a Polyamide II $(250 \mathrm{~mm} \times 4.6 \mathrm{~mm}$ i.d. $)$ normal-phase column from YMC Waters operating at $30{ }^{\circ} \mathrm{C}$. The mobile phase used was a mixture of n-hexane and ethyl acetate $(70: 30, v / v)$ at a flow rate of $1 \mathrm{~mL} / \mathrm{min}$, and the injection volume was $20 \mu \mathrm{L}$. The compounds were identified by chromatographic comparisons 
with authentic standards. Quantification was based on calibration curves obtained from commercial standards of each compound using the IS methodology. The results were expressed in mg per $100 \mathrm{~g}$ of dry weight (dw).

\subsection{Evaluation of bioactive properties}

\subsubsection{Samples preparation}

The methanolic extract was obtained from the dried plant material. The sample $(\approx 1 \mathrm{~g})$ was extracted by stirring with $25 \mathrm{~mL}$ of methanol $\left(25^{\circ} \mathrm{C}\right.$ at $\left.150 \mathrm{rpm}\right)$ for $1 \mathrm{~h}$ and subsequently filtered through Whatman No. 4 paper. The residue was then extracted with $25 \mathrm{~mL}$ of methanol $\left(25^{\circ} \mathrm{C}\right.$ at $\left.150 \mathrm{rpm}\right)$ for $1 \mathrm{~h}$. The combined methanolic extracts were evaporated at $40{ }^{\circ} \mathrm{C}$ (rotary evaporator Büchi R-210, Flawil, Switzerland) to dryness.

Methanolic extract was redissolved in methanol (final concentration, $5 \mathrm{mg} / \mathrm{mL}$ ) for antioxidant activity evaluation. The final solutions were further diluted to different concentrations to be submitted to distinct bioactivity evaluation in in vitro assays. The results were expressed in $\mathrm{EC}_{50}$ values (sample concentration providing $50 \%$ of antioxidant activity or 0.5 of absorbance in the reducing power assay) for antioxidant activity.

\subsubsection{Antioxidant activity}

\subsubsection{DPPH radical-scavenging activity}

DPPH radical-scaveging activity was performed using an ELX800 Microplate Reader (Bio-Tek Instruments, Inc; Winooski, VT, USA). The reaction mixture in each one of the 96-wells consisted of one of the different concentrations of the extracts (30 $\mu \mathrm{L})$ and aqueous methanolic solution $(80: 20 v / v, 270 \mu \mathrm{L})$ containing DPPH radicals $\left(6 \times 10^{-5}\right.$ 
$\mathrm{mol} / \mathrm{L}$ ). The mixture was left to stand for $60 \mathrm{~min}$ in the dark. The reduction of the DPPH radical was determined by measuring the absorption at $515 \mathrm{~nm}$ (Pinela et al., 2012). The radical scavenging activity (RSA) was calculated as a percentage of DPPH discolouration using the equation: $\% \mathrm{RSA}=\left[\left(A_{\mathrm{DPPH}}-A_{\mathrm{S}}\right) / A_{\mathrm{DPPH}}\right] \times 100$, where $A_{\mathrm{S}}$ is the absorbance of the solution when the sample extract has been added at a particular level, and $A_{\mathrm{DPPH}}$ is the absorbance of the DPPH solution. The extract concentration providing $50 \%$ of radical scavenging activity $\left(\mathrm{EC}_{50}\right)$ was calculated from the graph of RSA percentage against extract concentration. Trolox was used as a standard.

\subsubsection{Reducing power}

This methodology was performed using the Microplate Reader described above. The different concentrations of the extracts $(0.5 \mathrm{~mL})$ were mixed with sodium phosphate buffer $(200 \mathrm{mmol} / \mathrm{L}, \mathrm{pH} 6.6,0.5 \mathrm{~mL})$ and potassium ferricyanide $(1 \% \mathrm{w} / \mathrm{v}, 0.5 \mathrm{~mL})$. The mixture was incubated at $50{ }^{\circ} \mathrm{C}$ for $20 \mathrm{~min}$, and trichloroacetic acid $(10 \% \mathrm{w} / \mathrm{v}, 0.5 \mathrm{~mL})$ was added. The mixture $(0.8 \mathrm{~mL})$ was poured in the 48 -wells, as also deionized water $(0.8 \mathrm{~mL})$ and ferric chloride $(0.1 \% \mathrm{w} / v, 0.16 \mathrm{~mL})$, and the absorbance was measured at $690 \mathrm{~nm}$ (Pinela et al., 2012). The extract concentration providing 0.5 of absorbance $\left(\mathrm{EC}_{50}\right)$ was calculated from the graph of absorbance at $690 \mathrm{~nm}$ against extract concentration. Trolox was used as a standard.

\subsubsection{Inhibition of $\beta$-carotene bleaching}

A solution of $\beta$-carotene was prepared by dissolving $\beta$-carotene $(2 \mathrm{mg})$ in chloroform $(10 \mathrm{~mL})$. Two millilitres of this solution were pipetted into a round-bottom flask. After the chloroform was removed at $40{ }^{\circ} \mathrm{C}$ under vacuum, linoleic acid (40 mg), Tween 80 emulsifier (400 mg), and distilled water $(100 \mathrm{~mL})$ were added to the flask with vigorous 
shaking. Aliquots $(4.8 \mathrm{~mL})$ of this emulsion were transferred into different test tubes containing different concentrations of the extracts $(0.2 \mathrm{~mL})$. The tubes were shaken and incubated at $50{ }^{\circ} \mathrm{C}$ in a water bath. As soon as the emulsion was added to each tube, the zero time absorbance was measured at $470 \mathrm{~nm}$ (Pinela et al., 2012). $\beta$-Carotene bleaching inhibition was calculated using the following equation: ( $\beta$-carotene content after $2 \mathrm{~h}$ of assay/initial $\beta$-carotene content $) \times 100$. The extract concentration providing $50 \%$ antioxidant activity $\left(\mathrm{EC}_{50}\right)$ was calculated by interpolation from the graph of $\beta$ carotene bleaching inhibition percentage against extract concentration. Trolox was used as a standard.

\subsubsection{Inhibition of lipid peroxidation using thiobarbituric acid reactive substances} $(T B A R S)$

Brains were obtained from porcine (Sus scrofa), dissected and homogenized with a Polytron in ice-cold Tris- $\mathrm{HCl}$ buffer $(20 \mathrm{mM}, \mathrm{pH} 7.4)$ to produce a $1: 2(w / v)$ brain tissue homogenate that was centrifuged at $3000 \mathrm{~g}$ (Centorion K24OR refrigerated centrifuge) for $10 \mathrm{~min}$. An aliquot $(0.1 \mathrm{~mL})$ of the supernatant was incubated with the different concentrations of the extracts $(0.2 \mathrm{~mL})$ in the presence of $\mathrm{FeSO}_{4}(10 \mu \mathrm{M} ; 0.1 \mathrm{~mL})$ and ascorbic acid $(0.1 \mathrm{mM} ; 0.1 \mathrm{~mL})$ at $37^{\circ} \mathrm{C}$ for $1 \mathrm{~h}$. The reaction was stopped by the addition of trichloroacetic acid $(28 \%, w / v, 0.5 \mathrm{~mL})$, followed by thiobarbituric acid (TBA, $2 \%, w / v, 0.38 \mathrm{~mL}$ ), and the mixture was then heated at $80{ }^{\circ} \mathrm{C}$ for $20 \mathrm{~min}$. After centrifugation at $3000 \mathrm{~g}$ for $10 \mathrm{~min}$ to remove the precipitated protein, the color intensity of the malondialdehyde (MDA)-TBA complex in the supernatant was measured by its absorbance at $532 \mathrm{~nm}$ (Pinela et al., 2012). The inhibition ratio (\%) was calculated using the following formula: Inhibition ratio $(\%)=[(A-B) / A] \times 100 \%$, where $A$ and $B$ were the absorbance of the control and the compound solution, respectively. The extract 
concentration providing $50 \%$ lipid peroxidation inhibition $\left(\mathrm{EC}_{50}\right)$ was calculated from the graph of TBARS inhibition percentage against extract concentration. Trolox was used as a standard.

\subsection{Statistical analysis}

All extractions were performed in triplicate and each replicate was also analysed in triplicate. The results are expressed as means \pm standard deviations. All statistical tests were performed at a 5\% significance level using the SPSS software, version 19.0 (IBM Inc).

The fulfillment of the one-way ANOVA requirements, specifically the normal distribution of the residuals and the homogeneity of variance, were tested by the Shapiro-Wilk's and the Levene's tests, respectively. In the cases where statistical significance differences were identified, the dependent variable were compared using Tukey's honestly significant difference (homoscedasticity) or Tamhane's T2 (heteroscedasticity) multiple comparison tests.

Principal components analysis (PCA) was applied as pattern recognition unsupervised classification method. The construction of the matrix for PCA included 59 variables (corresponding to the evaluated parameters) and 27 samples (corresponding to the flowering stages). PCA transforms the original, measured variables into new uncorrelated variables called principal components. The first principal component covers as much of the variation in the data as possible. The second principal component is orthogonal to the first and covers as much of the remaining variation as possible, and so on (Patras et al., 2011). The number of dimensions kept for data analysis was evaluated by the respective eigenvalues (which should be greater than one), by the Cronbach's alpha parameter (that must be positive) and also by the total percentage of 
variance (that should be as higher as possible) explained by the number of components selected. The number of plotted dimensions was chosen to allow meaningful interpretations.

\section{Results and discussion}

\subsection{Chemical composition in hydrophilic compounds}

The results for soluble sugars composition are shown in Table 1. The soluble sugars in the three stages of maturation found were fructose, glucose, sucrose and trehalose, with prevalence of fructose and glucose. Except for trehalose $(1.50 \mathrm{~g} / 100 \mathrm{~g}$ dw in F1), the highest amounts of each quantified soluble sugar were present in the full flowering stage (F2). The fact that the highest values quantified for F2 was especially evident for glucose and fructose, the soluble sugars with higher sweeter power (despite fructose is twice as sweet as glucose) among the detected ones, might be related with the initiation of nectar production in this stage (Nookaraju et al., 2010).

Oxalic, quinic, malic, and citric acids were quantified in all the stages of maturation of O. microdasys flowers (Table 2). The highest content in organic acids $(6.2 \mathrm{~g} / 100 \mathrm{~g} \mathrm{dw})$ was found in the vegetative stage (F1), mostly due to quinic and citric acid contents. In fact, all the evaluated organic acids (except malic acid) tended to decrease with advanced flower maturity. The evolution of organic acids in this study corroborates the general principle stating that organic acids are used as respiratory substrates in mature stages (Moing et al., 2001).

The characterization of the phenolic compounds was performed by HPLC-DAD/ESIMS analysis, and data of the retention time, $\lambda_{\max }$, pseudomolecular ion, main fragment ions in $\mathrm{MS}^{2}$, tentative identification and concentration of phenolic acid derivatives and 
flavonoids are presented in Table 3. An exemplifying HPLC phenolic profile, recorded at $370 \mathrm{~nm}$, is presented in Figure $\mathbf{1}$ for F1 stage.

UV and mass spectra obtained by HPLC-DAD-ESI/MS analysis showed that the phenolic composition $O$. microdasys flowers were characterized by the presence of hydroxycinnamoyl derivatives and flavonols (kaempferol and isorhamnetin derivatives). Sugar substituents consisted of hexosides and rutinosides, as deduced from the losses of $162 \mathrm{Da}$ and $308 \mathrm{Da}$, respectively.

Thirteen compounds were detected, five of which were hydroxycinnamic acid derivatives. Peaks 1 and 2 were tentatively identified as caffeic acid derivatives, that were assigned according to their characteristic UV spectra, showing maximum wavelength around $326 \mathrm{~nm}$, and to the ions at $\mathrm{m} / \mathrm{z} 179$ ([caffeic acid-H]'), 161 ([caffeic acid- $\left.\left.-\mathrm{H}_{-} \mathrm{H}_{2} \mathrm{O}\right]^{-}\right)$and 135 ([caffeic acid- $\left.\left.\mathrm{CO}_{2}-\mathrm{H}\right]^{-}\right)$observed in their $\mathrm{MS}^{2}$ spectra. Similar reasoning can be applied to assign peak 3 as a coumaric acid derivative, and peaks 4 and 5 as ferulic acid derivatives. Based in its pseudomolecular ion $[\mathrm{M}-\mathrm{H}]^{-}$at $m / z$ 341, peak 1 was attributed to a hexosyl caffeic acid, although sugar position and nature could not be established. Similarly peak 4 can be attributed to a hexosyl ferulic acid.

Peaks 2, 3 and 5 correspond to equivalent compounds derived from one of the three hydroxycinnamic acids, i.e., caffeic, coumaric and ferulic acids. In all cases, a loss of $296 \mathrm{mu}$ is produced from the respective pseudomolecular ion to yield the hydroxycinnamic acid residue, although the nature of that loss could not be established, so that the structures of those peaks remain unknown.

The remaining phenolic compounds corresponded to kaempferol $\left(\lambda_{\max }\right.$ around $348 \mathrm{~nm}$ and $\mathrm{MS}^{2}$ fragment at $\left.m / z 285\right)$ and isorhamnetin $\left(\lambda_{\max }\right.$ around $354 \mathrm{~nm}$ and $\mathrm{MS}^{2}$ fragment at $m / z 315)$ derivatives. Peak $6\left([\mathrm{M}-\mathrm{H}]^{-}\right.$at $\left.m / z 579\right)$ could be interpreted as a kaempferol pentosyl-hexoside based on the fragments at $m / z 447$ ([M-H-132] $]^{-}$and at $m / z 285$ ([M- 
H-132-162]'. Peak 9 was positively identified as kaempferol-3-O-rutinoside according to its retention, mass and UV-vis characteristics and by comparison with a commercial standard. All the remaining compounds were isorhamnetin derivatives. Peak 7 , with a pseudo molecular ion $[\mathrm{M}-\mathrm{H}]^{-}$at $m / z 769$, releasing fragments at $m / z 623(-146 \mathrm{u}$; loss of deoxyhexosyl residue) and 315 (-146-308 u; loss of deoxyhexosyl + rutinosyl residues), could be assigned as isorhamnetin rhamnosyl-rutinoside. Peak 8 showed a pseudomolecular ion $[\mathrm{M}-\mathrm{H}]^{-}$at $\mathrm{m} / z$ 639, yielding a unique fragment at $\mathrm{m} / \mathrm{z}$ at 315 (isorhamnetin) from the loss of two hexosyl residues $(162+162 \mathrm{u})$. The position of the sugar substituents could not be definitely concluded, although it might be assumed that they could constitute a dissaccharide $O$-linked to the aglycone, since no fragment at $\mathrm{m} / \mathrm{z}$ 447 from the loss of one hexosyl moiety was observed. Thus, peak 8 was just assigned as an isorhamnetin $O$-dihexoside.

Peaks 10 and $11\left([\mathrm{M}-\mathrm{H}]^{-}\right.$at $m / z$ 623) release one $\mathrm{MS}^{2}$ fragment ion at $\mathrm{m} / \mathrm{z} 315$, consistent with the loss of a deoxyhexosyl-hexoside moiety (308 u). Peak 10 was positively identified as isorhamnetin-3-O-rutinoside according to its retention, mass and UV-vis characteristics by comparison with a commercial standard. Peak 11 was tentatively identified as isorhamnetin-3-O-robinobioside (i.e., rhamnosyl-galactoside), previously reported in Opuntia ficus-indica flowers (Leo et al., 2010).

Finally, peaks 12 and $13\left([\mathrm{M}-\mathrm{H}]^{-}\right.$at $\mathrm{m} / z$ 477) correspond to isorhamnetin derivatives with a hexosyl moiety. Peak 12 was positively identified as isorhamnetin-3-O-glucoside according to its retention, mass and UV-vis characteristics by comparison with a commercial standard. Peak 13 was tentatively identified as isorhamnetin-3-Ogalactoside, as previously reported in Opuntia genus (Leo et al., 2010).

Flavonoids, especially isorhamnetin derivatives, were the majority phenolic compounds present in these samples. F1 stage gave statistically significant higher amounts of all 
phenolic compounds, except hexosyl ferulic acid and kaempferol pentosyl-hexoside, which were higher in F3. Considering the total amounts as divided by subgroups of phenolic compounds, phenolic acids ( $2947 \pm 23 \mu \mathrm{g} / \mathrm{g}$ extract) were significantly higher in F1, similarly to the observed for flavonol derivatives $(23043 \pm 117 \mu \mathrm{g} / \mathrm{g}$ extract). F2 presented the lowest amounts, either in respect to phenolic acids $(1239 \pm 35 \mu \mathrm{g} / \mathrm{g}$ extract), as well as for flavonol derivatives $(4680 \pm 12 \mu \mathrm{g} / \mathrm{g}$ extract).

\subsection{Chemical composition in lipophilic compounds}

The results of fatty acids (FA) profiles are shown in Table 4. Besides those included in the table, caprylic acid (C8:0), capric acid (C10:0), tridecanoic acid (C13:0), myristoleic acid (C14:1), eicosatrienoic acid plus heneicosanoic acid (C20:3 + C21:0) and tricosanoic acid $(\mathrm{C} 23: 0)$ were also detected in trace amounts $(<0.2 \%)$. All fatty acids showed significant differences along the assayed maturity stages, except for lignoceric acid (C24:0; $p=0.382)$. Saturated fatty acids (SFA), particularly due to palmitic acid (C16:0) contents, predominated over unsaturated ones in all maturity stages, presenting highest values in F3. On the other hand, monounsaturated fatty acids (MUFA), mostly due to oleic acid (18:1) contribution, had maximum values in F2, while polyunsaturated fatty acids (PUFA), with relevance for linoleic and linolenic acids (C18:2 and C18:3), gave the highest values in F1. The detected profiles are similar to those commonly found in Opuntia genus (Ammar et al., 2012). Linoleic acid is the most prominent PUFA in the Western diet and previous studies showed health benefits in the prevention of cancer diseases (Whelan, 2008). $\alpha$-Linolenic acid is essential for human metabolism and has many beneficial effects, including the prevention of a number of diseases, such as coronary heart diseases, inflammation, autoimmune disorders, hypertension, presenting also hypotriglyceridemic effect (Bernal et al., 2011). The decrease verified 
along time for PUFA forms might be related with higher oxidative losses caused by the longer exposition to abiotic stress, since these molecules are more prone to oxidation.

Regarding tocopherols composition (Table 5), $\alpha$-tocopherol was, by far, the most abundant vitamer in the three flowering stages. Total tocopherols $(4.6 \mathrm{mg} / 100 \mathrm{~g} \mathrm{dw})$ and $\alpha-(3.6 \mathrm{mg} / 100 \mathrm{~g} \mathrm{dw}) \gamma-(0.37 \mathrm{mg} / 100 \mathrm{~g} \mathrm{dw})$ vitamers gave maximal values in $\mathrm{F} 1$, while $\beta$ - $(0.28 \mathrm{mg} / 100 \mathrm{~g} \mathrm{dw})$ and $\delta$-tocopherol $(0.30 \mathrm{mg} / 100 \mathrm{~g} \mathrm{dw})$ were highest in F3. Tocopherols are important natural antioxidants in plant foods, especially those rich in PUFA due to their capacity to scavenge lipid peroxyl radicals of unsaturated lipid molecules, preventing propagation of lipid peroxidation (Traber, 2007). Due to its role as free radical scavenger, vitamin $\mathrm{E}$ is also believed to protect against degenerative processes, such as cancer and cardiovascular diseases (Burton and Traber, 1990; Kagan et al., 2003).

\subsection{Evaluation of bioactive properties}

The antioxidant properties of the studied flowering stages were evaluated by DPPH radical scavenging capacity, reducing power $\left(\mathrm{Fe}^{3+}\right.$ into $\left.\mathrm{Fe}^{2+}\right)$ and inhibition of lipid peroxidation using $\beta$-carotene-linoleate model system and TBARS assay (Barros et al., 2010). With no exception, F1 gave the highest antioxidant activity for all assays, followed by F3. The results obtained in the evaluation of antioxidant activity are often associated with the phenolic composition (Cheung et al., 2003; Li et al., 2014). The results presented herein are in agreement with this premise, since F1, the flowering stage with highest phenolic acid and flavonol contents gave also the most powerful antioxidant activity (DPPH scavenging activity: $\mathrm{EC}_{50}=0.70 \mathrm{mg} / \mathrm{mL}$, reducing power: $\mathrm{EC}_{50}=0.169 \mathrm{mg} / \mathrm{mL}, \beta$-carotene bleaching inhibition: $\mathrm{EC}_{50}=0.126 \mathrm{mg} / \mathrm{mL}$, and TBARS inhibition: $\mathrm{EC}_{50}=0.050 \mathrm{mg} / \mathrm{mL}$ ). On the other hand, the flowering stage with 
the lowest contents in phenolic acids and flavonols presented the worst results in all antioxidant activity assays (DPPH scavenging activity: $\mathrm{EC}_{50}=1.00 \mathrm{mg} / \mathrm{mL}$, reducing power: $\mathrm{EC}_{50}=0.356 \mathrm{mg} / \mathrm{mL}, \beta$-carotene bleaching inhibition: $\mathrm{EC}_{50}=0.28 \mathrm{mg} / \mathrm{mL}$, and TBARS inhibition: $\mathrm{EC}_{50}=0.141 \mathrm{mg} / \mathrm{mL}$ ).

\subsection{Principal Components Analysis}

In order to have a more integrated approach regarding the differences in chemical profiles and antioxidant activity for the three assayed flowering stages, considering the results obtained for all the parameters simultaneously, a principal components analysis (PCA) was applied.

The plot of component loadings (Figure 2), indicates that the first two dimensions (first: Cronbach's $\alpha, 0.984$; eigenvalue, 31.032; second: Cronbach's $\alpha, 0.973$; eigenvalue, 22.854) account for most of the variance of all quantified variables (52.60 and $38.74 \%$, respectively). Only two dimensions were plotted, because the inclusion of additional dimensions would not allow a meaningful interpretation. Groups corresponding to each flowering stage (F1, F2 and F3) were clearly individualized, as it could be expected from Tables 1-6 (it should be reminded that only the fatty acid C24:0 gave no statistical differences among flowering stages). Group corresponding to F1 is mainly characterized by the high levels in quinic acid, organic acids, hexosyl caffeic acid, kaempferol-3-O-rutinoside, isorhamnetin dihexoside, C14:1, C18:3, PUFA, $\alpha$ tocopherol and $\gamma$-tocopherol, and low contents in malic acid, C8:0, C10:0, C16:0 and C20:1. F2, by its side, distinguished for having high contents in fructose, glucose, total soluble sugars, low contents in isorhamnetin-3-O-rutinoside, isorhamnetin rhamonsylrutinoside, $\mathrm{C} 12: 0, \mathrm{C} 13: 0, \mathrm{C} 18: 1, \mathrm{MUFA}$ and $\beta$-tocopherol and also for having low reducing power, TBARS formation inhibition and $\beta$-carotene bleaching inhibition. 
Finally, the most divergent characteristics for F3 were its high contents in hexosyl ferulic acid, C20:0, C20:2 and SFA, and low amounts in citric acid, trehalose, isorhamnetin-3-O-galactoside and C23:0.

\section{Conclusion}

The three assayed flowering stages displayed identical chemical profiles from a qualitative point of view; except for the fact that F3 was the only stage presenting C20:2. The three stages presented exactly the same soluble sugars, organic acids, phenolic compounds, fatty acids and tocopherols. Nevertheless, the amounts in each stage showed statistically significant differences, which were reflected in the antioxidant activity results. In fact, the extracts of $\mathrm{F} 1$ proved to have the highest radical scavenging activity and reducing power, in agreement with their higher amounts of phenolic acids and flavoinds, and also the most effective lipid peroxidation inhibition, (as shown in $\beta$-carotene bleaching inhibition and TBARS formation inhibition), as expected from their higher amounts in tocopherols and PUFA. These differences were meaningfully reflected in the applied PCA, as it could be observed by the distribution of the biplot markers in different clusters (corresponding to each flowering stage), which allowed the prompt observation of all significant differences in an integrated manner. The detected differences might be useful for the selection of a specific flowering stage concerning its incorporation in functional foods.

\section{Acknowledgements}

The authors are grateful to Fundação para a Ciência e a Tecnologia (FCT, Portugal) for financial support to CIMO (strategic project PEst-OE/AGR/UI0690/2011), João C.M. Barreira (SFRH/BPD/72802/2010 grant) and L. Barros ("Compromisso para a Ciência 
2008" contract). The GIP-USAL is financially supported by the Spanish Government through the Consolider-Ingenio 2010 Programme (FUN-C-FOOD, CSD2007-00063).

\section{References}

Alimi, H, Hfaiedh, N., Bouoni, Z., Sakly, M., \& Ben Rhouma, K. (2011). Evaluation of antioxidant and antiulcerogenic activities of Opuntia ficus indica $f$. inermis flowers extract in rats. Environmental Toxicology and Pharmacology, 32, 406416.

Ammar, I., Ennouri, M., Khemakhem, B., Yangui, T., \& Attia, H. (2012). Variation in chemical composition and biological activities of two species of Opuntia flowers at four stages of flowering. Industrial Crops and Products, 37, 34-40.

Barros, L., Carvalho, A.M., Sá Morais, J., \& Ferreira, Isabel C.F.R. (2010). Strawberrytree, blackthorn and rose fruits: Detailed characterization in nutrients and phytochemicals with antioxidant properties. Food Chemistry, 120, 247-254.

Barros, L., Pereira, C., \& Ferreira, Isabel C.F.R. (2013). Optimized analysis of organic acids in edible mushrooms from Portugal by ultra fast liquid chromatography and photodiode array detection. Food Analytical Methods, 6, 309-316.

Bernal, J., Mendiola, J.A., Ibáñez, E., \& Cifuentes, A. (2011). Advanced analysis of nutraceuticals. Journal of Pharmaceutaical and Biomedical Analysis, 55, 758774.

Burton, G.W. \& Traber, M.G. (1990). Vitamin E: Antioxidant activity, biokinetics, and bioavailability. Annual Review of Nutrition, 10, 357-382.

Carocho, M. \& Ferreira, Isabel C.F.R. (2013). A review on antioxidants, prooxidants and related controversy: Natural and synthetic compounds, screening and analysis 
methodologies and future perspectives. Food and Chemical Toxicology, 51, 1525.

Cheung, L.M., Cheung, P.C.K., \& Ooi, V.E.C. (2003). Antioxidant activity and total phenolics of edible mushroom extracts. Food Chemistry, 81, 249-255.

Feugang, J.M., Konarski, P., Zou, D., Stintzing, F.C., \& Zou, C. (2006). Nutritional and medicinal use of Cactus pear (Opuntia spp.) cladodes and fruits. Frontiers in Bioscience, 11, 2574-2589.

Galati, E.M., Tripodo, M.M., Trovato, A., Miceli, N., \& Monforte, M.T. (2002). Biological effect of Opuntia ficus indica (L.) Mill. (Cactaceae) waste matter. Journal of Ethnopharmacology, 79, 17-21.

Heim, K.E., Tagliaferro, A.R., \& Bobilya, D.J. (2002). Flavonoid antioxidants: chemistry, metabolism and structure-activity relationships. Nutritional Biochemistry, 13, 572-584.

Kagan, V.E., Kuzmenko, A.I., Shvedova, A.A., Kisin, E.R., Li, R., Martin, I., Quinn, P.J., Tyurin, V.A., Tyurina, Y.Y., \& Yalowich, J.C. (2003). Direct evidence for recycling of myeloperoxidase-catalyzed phenoxyl radicals of a vitamin $\mathrm{E}$ homologue,2,2,5,7,8-pentamethyl-6-hydroxy chromane, by ascorbate/dihydrolipoate in living HL-60 cells. Biochimica et Biophysica Acta, $1620,72-84$

Leo, M.D., Abreu, M.B.D., Pawlowska, A.M., Cioni, P.L., \& Braca, A. (2010). Profiling the chemical content of Opuntia ficus-indica flowers by HPLC-PDAESI-MS and GC/EIMS analyses. Phytochemistry Letters, 3, 48-52.

Li, A.-N., Li, S., Li H.-B., Xu, D.-P., Xu, X.-R., Chen, F. (2014). Total phenolic contentes and antioxidant capacities of 51 edible and wild flowers. Journal of Functional Foods, 6, 319-330. 
Moing, A., Renaud, C., Gaudillère, M., Raymond, P., Roudeillac, P., \& DenoyesRothan, B. (2001). Biochemical changes during fruit development of four strawberry cultivars. Journal of the American Society of Horticulture Sciences. 126, 394-403.

Nookaraju, A., Upadhyaya, C.P., Pandey, S.K., Young, K.E., Hong, S.J., Park, S.K., \& Park, S.W. (2010). Molecular approaches for enhancing sweetness in fruits and vegetables. Scientia Horticulturae, 127, 1-15.

Pallarès, V., Fernández-Iglesias, A., Cedó, L., Castell-Auví, A., Pinent, M., Ardévol, A., Salvadó, M.J., Garcia-Vallvé, S., \& Blay, M. (2013). Grape seed procyanidin extract reduces the endotoxic effects induced by lipopolysaccharide in rats. Free Radical Biology and Medicine, 60,107-114.

Patras, A., Brunton, N.P., Downey, G., Rawson, A., Warriner, K., \& Gernigon, G. (2011). Application of principal component and hierarchical cluster analysis to classify fruits and vegetables commonly consumed in Ireland based on in vitro antioxidant activity. Journal of Food Composition and Analysis, 24, 250-256.

Pinela, J., Barros, L., Dueñas, M., Carvalho, A.M., Santos-Buelga, C., \& Ferreira, Isabel C.F.R. (2012). Antioxidant activity, ascorbic acid, phenolic compounds and sugars of wild and commercial Tuberaria lignosa samples: effects of drying and oral preparation methods. Food Chemistry, 135, 1028-1035.

Senanayake, S.P.J.N. (2013). Green tea extract: Chemistry, antioxidant properties and food applications - A review. Journal of Functional Foods, 5, 1529-1541.

Stintzing, F.C. \& Carle, R. (2005). Cactus stems (Opuntia spp.): A review on their chemistry, technology, and uses. Molecular Nutrition \& Food Research, 49, 175194. 
Traber, M.G. (2007). Vitamin E regulatory mechanisms. Annual Review of Nutrition, $27,347-362$.

Whelan, J. (2008). The health implications of changing linoleic acid intakes. Prostaglandins, Leukotrienes and Essential Fatty Acids, 79, 165-167.

Yeddes, N., Chérif, J.K., Guyot, S., Baron, A., \& Trabelsi-Ayadi, M. (2014). Phenolic profile of Tunisian Opuntia ficus indica thornless form flowers via chromatographic and spectral analysis by reversed phase-high performance liquid chromatography-UV-photodiode array and electrospray ionization-mass spectrometer. International Journal of Food Properties, 17, 741-751. 
Table1. Soluble sugars composition $(\mathrm{g} / 100 \mathrm{~g} \mathrm{dw})$ in three stages of flowering (F1-F3) of Opuntia microdasys (mean $\pm \mathrm{SD})$.

\begin{tabular}{llccccc}
\hline & & Fructose $^{1}$ & Glucose $^{1}$ & Sucrose $^{1}$ & Trehalose $^{1}$ & Soluble sugars $^{1}$ \\
\hline & F1 & $2.17 \pm 0.03 \mathrm{~b}$ & $2.42 \pm 0.05 \mathrm{c}$ & $1.61 \pm 0.05 \mathrm{~b}$ & $1.50 \pm 0.04 \mathrm{a}$ & $7.7 \pm 0.1 \mathrm{~b}$ \\
Flowering stage & $\mathrm{F} 2$ & $5.96 \pm 0.02 \mathrm{a}$ & $4.97 \pm 0.03 \mathrm{a}$ & $1.90 \pm 0.02 \mathrm{a}$ & $1.42 \pm 0.04 \mathrm{~b}$ & $14.2 \pm 0.1 \mathrm{a}$ \\
& $\mathrm{F} 3$ & $2.12 \pm 0.02 \mathrm{c}$ & $2.89 \pm 0.03 \mathrm{~b}$ & $0.61 \pm 0.01 \mathrm{c}$ & $1.08 \pm 0.01 \mathrm{c}$ & $6.7 \pm 0.1 \mathrm{c}$ \\
\hline Homoscedasticity $^{2}$ & $p$-value & 0.287 & 0.008 & $<0.001$ & 0.002 & 0.308 \\
\hline One-way ANOVA $^{3}$ & $p$-value & $<0.001$ & $<0.001$ & $<0.001$ & $<0.001$ & $<0.001$ \\
\hline
\end{tabular}

${ }^{1}$ Means were evaluated using Tukey (homoscedasticity) or Tamhane's T2 (heteroscedasticity) post hoc tests.

${ }^{2}$ Homoscedasticity among cultivars was tested by means of the Levene test: homoscedasticity, $p$-value $>0.05$; heteroscedasticity, $p$-value $<0.05$.

${ }^{3} p<0.05$ indicates that the mean value of the evaluated parameter of at least one flowering stage differs from the others (in this case multiple comparison tests were performed). 
Table 2. Organic acids composition (g/100 g dw) in three stages (F1-F3) of flowering of Opuntia microdasys (mean $\pm \mathrm{SD}$ ).

\begin{tabular}{llccccc}
\hline & & Oxalic acid $^{1}$ & Quinic acid $^{1}$ & Malic acid $^{1}$ & Citric acid $^{1}$ & Organic acids $^{1}$ \\
\hline Flowering stage & F1 & $1.13 \pm 0.01 \mathrm{a}$ & $2.37 \pm 0.05 \mathrm{a}$ & $0.67 \pm 0.01 \mathrm{c}$ & $2.08 \pm 0.02 \mathrm{a}$ & $6.2 \pm 0.2 \mathrm{a}$ \\
& $\mathrm{F} 3$ & $0.72 \pm 0.01 \mathrm{c}$ & $0.41 \pm 0.01 \mathrm{~b}$ & $1.10 \pm 0.01 \mathrm{a}$ & $2.09 \pm 0.05 \mathrm{a}$ & $4.3 \pm 0.1 \mathrm{~b}$ \\
\hline Homoscedasticity $^{2}$ & $p$-value & 0.014 & $<0.001$ & 0.008 & 0.001 & 0.005 \\
\hline One-way ANOVA $^{3}$ & $p$-value & $<0.001$ & $<0.001$ & $<0.001$ & $<0.001$ & $<0.001$ \\
\hline
\end{tabular}

Means were evaluated using Tukey (homoscedasticity) or Tamhane's T2 (heteroscedasticity) post hoc tests.

${ }^{2}$ Homoscedasticity among cultivars was tested by means of the Levene test: homoscedasticity, $p$-value $>0.05$; heteroscedasticity, $p$-value $<0.05$.

${ }^{3} p<0.05$ indicates that the mean value of the evaluated parameter of at least one flowering stage differs from the others (in this case multiple comparison tests were performed). 
Table 3. Retention time (Rt), wavelengths of maximum absorption $\left(\lambda_{\max }\right)$, mass spectral data, relative abundances of fragment ions, tentative identification and quantification of the phenolic compounds in three stages of flowering (F1-F3) of Opuntia microdasys (mean \pm SD).

\begin{tabular}{|c|c|c|c|c|c|c|c|c|c|c|}
\hline \multirow[t]{2}{*}{ Peak } & \multirow{2}{*}{$\begin{array}{c}\mathrm{Rt} \\
(\min )\end{array}$} & \multirow{2}{*}{$\begin{array}{l}\lambda_{\max } \\
(\mathrm{nm})\end{array}$} & \multirow{2}{*}{$\begin{array}{l}\text { Molecular ion } \\
{[\mathrm{M}-\mathrm{H}]^{-}(\mathrm{m} / z)}\end{array}$} & \multirow[t]{2}{*}{$\operatorname{MS}^{2}(m / z)$} & \multirow[t]{2}{*}{ Tentative identification } & \multicolumn{3}{|c|}{$\begin{array}{l}\text { Quantification }^{1} \\
(\mu \mathrm{g} / \mathrm{g} \text { extract })\end{array}$} & \multirow{2}{*}{$\begin{array}{c}\text { Homoscedasticity }^{2} \\
p \text {-value }\end{array}$} & $\begin{array}{l}\text { One-way } \\
\text { ANOVA }^{3} \\
\end{array}$ \\
\hline & & & & & & F1 & F2 & F3 & & $p$-value \\
\hline 1 & 6.1 & 326 & 341 & 179(71), 161(90), 135(19) & Hexosyl caffeic acid & $700 \pm 5 \mathrm{a}$ & $264 \pm 1 b$ & $254 \pm 3 \mathrm{c}$ & 0.007 & $<0.001$ \\
\hline 2 & 6.6 & 326 & 475 & 179(16), 161(39), 135(13) & Caffeic acid derivative & $469 \pm 9$ a & $255 \pm 8 \mathrm{c}$ & $309 \pm 3 b$ & 0.012 & $<0.001$ \\
\hline 3 & 9.8 & 312 & 459 & $163(38), 145(100)$ & $p$-Coumaric acid derivative & $178 \pm 1 \mathrm{a}$ & $65 \pm 1 \mathrm{c}$ & $105 \pm 1 \mathrm{~b}$ & 0.073 & $<0.001$ \\
\hline 4 & 10.4 & 328 & 355 & 193(17), 175(100), 149(5) & Hexosyl ferulic acid & $363 \pm 7 b$ & $364 \pm 4 b$ & $605 \pm 4 \mathrm{a}$ & 0.023 & $<0.001$ \\
\hline 5 & 12.1 & 326 & 489 & $\begin{array}{l}337(8), 295(17), 235(52) \\
193(78), 175(60), 149(8)\end{array}$ & Ferulic acid derivative & $786 \pm 8 \mathrm{a}$ & $291 \pm 2 \mathrm{c}$ & $487 \pm 29 \mathrm{~b}$ & $<0.001$ & $<0.001$ \\
\hline 6 & 12.9 & 354 & 579 & $447(60), 285(40)$ & Kaempferol pentosyl-hexoside & $266 \pm 7 b$ & $111 \pm 1 \mathrm{c}$ & $395 \pm 6 \mathrm{a}$ & 0.002 & $<0.001$ \\
\hline 7 & 19.8 & 354 & 769 & $623(2), 315(78)$ & $\begin{array}{r}\text { Isorhamnetin rhamnosyl- } \\
\text { rutinoside }\end{array}$ & $3765 \pm 22 \mathrm{a}$ & $962 \pm 2 \mathrm{c}$ & $3518 \pm 33 b$ & 0.001 & $<0.001$ \\
\hline 8 & 20.5 & 356 & 639 & $315(100)$ & Isorhamnetin dihexoside & $565 \pm 9$ a & $268 \pm 1 b$ & $222 \pm 6 \mathrm{c}$ & $<0.001$ & $<0.001$ \\
\hline 9 & 21.2 & 348 & 593 & $285(100)$ & Kaempferol-3-O-rutinoside & $442 \pm 3$ a & $210 \pm 1 \mathrm{~b}$ & $159 \pm 3 \mathrm{c}$ & $<0.001$ & $<0.001$ \\
\hline 10 & 24.4 & 352 & 623 & $315(100)$ & Isorhamnetin-3-O-rutinoside & $6960 \pm 48$ a & $559 \pm 2 \mathrm{c}$ & $5167 \pm 50 \mathrm{~b}$ & $<0.001$ & $<0.001$ \\
\hline 11 & 25.0 & 354 & 623 & $315(90)$ & Isorhamnetin-3-O-robinobioside & $8417 \pm 51 \mathrm{a}$ & $542 \pm 3 \mathrm{c}$ & $3863 \pm 56 \mathrm{~b}$ & 0.001 & $<0.001$ \\
\hline 12 & 26.0 & 354 & 477 & $315(100)$ & Isorhamnetin-3-O-glucoside & $2419 \pm 27 \mathrm{a}$ & $1836 \pm 8 \mathrm{~b}$ & $1500 \pm 17 \mathrm{c}$ & $<0.001$ & $<0.001$ \\
\hline \multirow[t]{3}{*}{13} & 26.6 & 354 & 477 & $315(100)$ & Isorhamnetin-3-O-galactoside & $210 \pm 2 \mathrm{a}$ & $192 \pm 3 b$ & $98 \pm 2 \mathrm{c}$ & 0.233 & $<0.001$ \\
\hline & & & & & Phenolic acids & $2947 \pm 23$ a & $1239 \pm 35 \mathrm{c}$ & $1760 \pm 5 \mathrm{~b}$ & 0.044 & $<0.001$ \\
\hline & & & & & Flavonoids & $23043 \pm 117 a$ & $4680 \pm 12 \mathrm{c}$ & $14921 \pm 142 b$ & 0.010 & $<0.001$ \\
\hline
\end{tabular}

\footnotetext{
${ }^{1}$ Means were evaluated using Tukey (homoscedasticity) or Tamhane's T2 (heteroscedasticity) post hoc tests.
${ }^{2}$ Homoscedasticity among cultivars was tested by means of the Levene test: homoscedasticity, $p$-value $>0.05$; heteroscedasticity, $p$-value $<0.05$.

${ }^{3} p<0.05$ indicates that the mean value of the evaluated parameter of at least one flowering stage differs from the others (in this case multiple comparison tests were performed)
} 
Table 4. Fatty acids composition (relative percentage) in three stages of flowering (F1F3) of Opuntia microdasys (mean \pm SD).

\begin{tabular}{|c|c|c|c|c|c|}
\hline \multirow{2}{*}{ Fatty acids* } & \multicolumn{3}{|c|}{ Flowering stage $^{1}$} & \multirow{2}{*}{$\frac{\text { Homoscedasticity }^{2}}{p \text {-value }}$} & \multirow{2}{*}{$\frac{\text { One-way ANOVA }^{3}}{p \text {-value }}$} \\
\hline & (F1) & $(\mathrm{F} 2)$ & (F3) & & \\
\hline C6:0 & $0.20 \pm 0.01 \mathrm{~b}$ & $0.10 \pm 0.01 \mathrm{c}$ & $0.27 \pm 0.03 \mathrm{a}$ & 0.024 & $<0.001$ \\
\hline $\mathrm{C} 12: 0$ & $0.89 \pm 0.04 \mathrm{a}$ & $0.56 \pm 0.04 \mathrm{c}$ & $0.81 \pm 0.05 \mathrm{~b}$ & 0.134 & $<0.001$ \\
\hline C14:0 & $2.05 \pm 0.03 \mathrm{a}$ & $1.44 \pm 0.03 \mathrm{c}$ & $1.81 \pm 0.05 \mathrm{~b}$ & 0.063 & $<0.001$ \\
\hline $\mathrm{C} 15: 0$ & $0.71 \pm 0.05 \mathrm{a}$ & $0.55 \pm 0.04 \mathrm{~b}$ & $0.37 \pm 0.05 \mathrm{c}$ & $<0.001$ & $<0.001$ \\
\hline C16:0 & $32 \pm 1 \mathrm{c}$ & $36 \pm 1 \mathrm{~b}$ & $39 \pm 1$ a & 0.015 & $<0.001$ \\
\hline C16:1 & $0.36 \pm 0.03 \mathrm{~b}$ & $0.48 \pm 0.05 \mathrm{a}$ & $0.28 \pm 0.03 \mathrm{c}$ & $<0.001$ & $<0.001$ \\
\hline $\mathrm{C} 17: 0$ & $0.61 \pm 0.04 \mathrm{a}$ & $0.50 \pm 0.05 \mathrm{~b}$ & $0.38 \pm 0.03 \mathrm{c}$ & 0.011 & $<0.001$ \\
\hline C18:0 & $4.3 \pm 0.1 \mathrm{a}$ & $4.4 \pm 0.2 \mathrm{a}$ & $4.0 \pm 0.1 \mathrm{~b}$ & 0.052 & $<0.001$ \\
\hline C18:1 & $9.0 \pm 0.3 \mathrm{c}$ & $11.2 \pm 0.3 \mathrm{a}$ & $9.8 \pm 0.2 b$ & 0.136 & $<0.001$ \\
\hline C18:2 & $20 \pm 1 \mathrm{a}$ & $18.6 \pm 0.2 \mathrm{~b}$ & $16.5 \pm 0.1 \mathrm{c}$ & $<0.001$ & $<0.001$ \\
\hline C18:3 & $18.8 \pm 0.1 \mathrm{a}$ & $15.6 \pm 0.5 \mathrm{~b}$ & $15.4 \pm 0.2 \mathrm{~b}$ & 0.032 & $<0.001$ \\
\hline $\mathrm{C} 20: 0$ & $4.2 \pm 0.3 \mathrm{~b}$ & $3.9 \pm 0.2 \mathrm{~b}$ & $4.6 \pm 0.1 \mathrm{a}$ & 0.147 & $<0.001$ \\
\hline C20:1 & $0.10 \pm 0.01 \mathrm{c}$ & $0.20 \pm 0.01 \mathrm{~b}$ & $0.31 \pm 0.03 \mathrm{a}$ & 0.013 & $<0.001$ \\
\hline C20:2 & nd & nd & $0.46 \pm 0.03$ & - & - \\
\hline $\mathrm{C} 22: 0$ & $4.4 \pm 0.5 \mathrm{a}$ & $3.8 \pm 0.2 \mathrm{~b}$ & $3.3 \pm 0.1 \mathrm{c}$ & $<0.001$ & $<0.001$ \\
\hline $\mathrm{C} 24: 0$ & $2.0 \pm 0.4$ & $1.8 \pm 0.3$ & $1.9 \pm 0.1$ & 0.005 & 0.382 \\
\hline SFA & $52 \pm 1 \mathrm{c}$ & $54 \pm 1 \mathrm{~b}$ & $57 \pm 1 \mathrm{a}$ & 0.058 & $<0.001$ \\
\hline MUFA & $9.6 \pm 0.3 \mathrm{c}$ & $11.8 \pm 0.4 \mathrm{a}$ & $10.4 \pm 0.2 \mathrm{~b}$ & 0.171 & $<0.001$ \\
\hline PUFA & $39 \pm 1 \mathrm{a}$ & $34 \pm 1 \mathrm{~b}$ & $32 \pm 1 \mathrm{c}$ & 0.004 & $<0.001$ \\
\hline
\end{tabular}

*Caproic acid (C6:0); lauric acid (C12:0); myristic acid (C14:0); pentadecanoic acid (C15:0); palmitic acid (C16:0); palmitoleic acid (C16:1); heptadecanoic acid (C17:0); stearic acid (C18:0); oleic acid (C18:1); linoleic acid (C18:2); linolenic acid (C18:3); arachidic acid (C20:0); eicosenoic acid (C20:1c); eicosadienoic acid (C20:2); behenic acid (C22:0); lignoceric acid (C24:0).

${ }^{1}$ Means were evaluated using Tukey (homoscedasticity) or Tamhane's T2 (heteroscedasticity) post hoc tests.

${ }^{2}$ Homoscedasticity among cultivars was tested by means of the Levene test: homoscedasticity, $p$-value $>0.05$; heteroscedasticity, $p$-value $<0.05$.

${ }^{3} p<0.05$ indicates that the mean value of the evaluated parameter of at least one flowering stage differs from the others (in this case multiple comparison tests were performed). 
Table 5. Tocopherols composition (mg/100 g dw) in three stages (F1-F3) of flowering of Opuntia microdasys (mean $\pm \mathrm{SD}$ ).

\begin{tabular}{llccccc}
\hline & & $\alpha$-tocopherol & $\beta$-tocopherol & $\gamma$-tocopherol & & $\delta$-tocopherol \\
& F1 & $3.6 \pm 0.1 \mathrm{a}$ & $0.28 \pm 0.01 \mathrm{~b}$ & $0.36 \pm 0.01 \mathrm{a}$ & $0.30 \pm 0.01 \mathrm{~b}$ & $4.6 \pm 0.1 \mathrm{a}$ \\
Flowering stage & $\mathrm{F} 2$ & $1.33 \pm 0.04 \mathrm{c}$ & $0.13 \pm 0.01 \mathrm{c}$ & $0.12 \pm 0.01 \mathrm{c}$ & $0.16 \pm 0.01 \mathrm{c}$ & $1.7 \pm 0.1 \mathrm{c}$ \\
& $\mathrm{F} 3$ & $1.5 \pm 0.1 \mathrm{~b}$ & $0.34 \pm 0.02 \mathrm{a}$ & $0.16 \pm 0.01 \mathrm{~b}$ & $0.50 \pm 0.02 \mathrm{a}$ & $2.5 \pm 0.2 \mathrm{~b}$ \\
\hline Homoscedasticity $^{2}$ & $p$-value & 0.005 & 0.031 & 0.012 & 0.001 & 0.009 \\
\hline One-way ANOVA $^{3}$ & $p$-value & $<0.001$ & $<0.001$ & $<0.001$ & $<0.001$ & $<0.001$ \\
\hline
\end{tabular}

${ }^{1}$ Means were evaluated using Tukey (homoscedasticity) or Tamhane's T2 (heteroscedasticity) post hoc tests.

${ }^{2}$ Homoscedasticity among cultivars was tested by means of the Levene test: homoscedasticity, $p$-value $>0.05$; heteroscedasticity, $p$-value $<0.05$.

${ }_{p<0.05}^{3}$ indicates that the mean value of the evaluated parameter of at least one flowering stage differs from the others (in this case multiple comparison tests were performed). 
Table 6. Antioxidant activity of methanolic extracts obtained from three stages of flowering (F1-F3) of Opuntia microdasys (mean \pm SD).

\begin{tabular}{|c|c|c|c|c|c|}
\hline & & \multicolumn{4}{|c|}{ Antioxidant assays $\left(\mathrm{EC}_{50}, \mathrm{mg} / \mathrm{mL}\right)^{1}$} \\
\hline & & $\begin{array}{c}\text { DPPH scavenging } \\
\text { activity }^{2}\end{array}$ & $\begin{array}{c}\text { Reducing } \\
\text { power }^{2}\end{array}$ & $\begin{array}{c}\beta \text {-carotene bleaching } \\
\text { inhibition }^{2}\end{array}$ & $\begin{array}{c}\text { TBARS } \\
\text { inhibition }^{2}\end{array}$ \\
\hline \multirow{3}{*}{ Flowering stage } & F1 & $0.70 \pm 0.03 \mathrm{c}$ & $0.169 \pm 0.002 \mathrm{c}$ & $0.126 \pm 0.004 \mathrm{c}$ & $0.050 \pm 0.001 \mathrm{c}$ \\
\hline & $\mathrm{F} 2$ & $1.00 \pm 0.01 \mathrm{a}$ & $0.356 \pm 0.003 \mathrm{a}$ & $0.28 \pm 0.01 \mathrm{a}$ & $0.141 \pm 0.003 \mathrm{a}$ \\
\hline & F3 & $0.88 \pm 0.02 \mathrm{~b}$ & $0.200 \pm 0.002 \mathrm{~b}$ & $0.15 \pm 0.01 \mathrm{~b}$ & $0.059 \pm 0.001 \mathrm{~b}$ \\
\hline Homoscedasticity $^{3}$ & $p$-value & 0.018 & 0.826 & 0.008 & 0.141 \\
\hline One-way ANOVA ${ }^{4}$ & $p$-value & $<0.001$ & $<0.001$ & $<0.001$ & $<0.001$ \\
\hline
\end{tabular}

${ }^{1} \mathrm{EC}_{50}$ values correspond to the sample concentration achieving $50 \%$ of antioxidant activity or 0.5 of absorbance in reducing power assay. In each row different letters mean significant differences $(p<0.05)$.

${ }^{2}$ Means were evaluated using Tukey (homoscedasticity) or Tamhane's T2 (heteroscedasticity) post hoc tests.

${ }^{3}$ Homoscedasticity among cultivars was tested by means of the Levene test: homoscedasticity, $p$-value $>0.05$; heteroscedasticity, $p$-value $<0.05$.

${ }^{4} p<0.05$ indicates that the mean value of the evaluated parameter of at least one flowering stage differs from the others (in this case multiple comparison tests were performed). 
Figure 1. HPLC chromatogram of the phenolic compounds of Opuntia microdasys flowers at the assayed flowering stages recorded at $370 \mathrm{~nm}$ : F1, black dashed line; F2, grey line; F3, black line. 1- Hexosyl caffeic acid; 2- Caffeic acid derivative; 3- $p$ Coumaric acid derivative; 4- Hexosyl ferulic acid; 5- Ferulic acid derivative; 6Kaempferol pentosyl-hexoside; 7- Isorhamnetin rhamnosyl-rutinoside; 8- Isorhamnetin dihexoside; 9- Kaempferol-3-O-rutinoside; 10- Isorhamnetin-3-O-rutinoside; 11Isorhamnetin-3-O-robinobioside; 12- Isorhamnetin-3-O-glucoside; 13- Isorhamnetin-3$O$-galactoside.

Figure 2. Biplot of objects and component loadings using flowering stage as labeling variable. 